\title{
The Effect of Individual and Legal Persons' Trading on Creation of Price Bubble in Tehran Stock Exchange (TSE) Market
}

\author{
Mir Feyz Fallahshams ${ }^{1}$, Meysam Alimohammadi ${ }^{2}$, Hamidreza Kordlouie ${ }^{3}$, Nader Naghshineh ${ }^{3}$ \\ ${ }^{1}$ Islamic Azad University, Tehran Central Branch, Iran \\ ${ }^{2}$ University of Economic Sciences, Tehran, Iran \\ ${ }^{3}$ Islamic Azad University, Islamshahr Branch, Tehran, Iran \\ Correspondence: Hamidreza Kordlouie, Islamic Azad University, Islamshahr Branch, Tehran, Iran
}

Received: June 9, 2014

Accepted: June 16, 2014

Available online: July 7, 2014

doi:10.11114/aef.v1i2.434

URL: http://dx.doi.org/10.11114/aef.v1i2.434

\begin{abstract}
This paper examines the effect of transactions carried out by legal persons or individuals on the formation of price bubbles for the companies listed in Tehran Exchange Market (TSE). At first through such tests as rows, skewness, stretching, and duration dependence, it was found out that price bubbles were formed in TSE in the span of time between May 2012 and November 2012. In this period, the prices were studied day by day, as well as in 5-minute time series. After doing bubble detection tests, the researchers divided the sampled companies under two categories of companies speculated to have bubbles and companies without bubbles. The study continued with investigating the effect of the behavior of individuals and legal persons on the formation of price bubbles. In so doing, their data on the transactions of individuals and legal persons were provided in 5-minute time series. The binary logit regression model was then put to use so to find out the effect size of these groups according to the data available. The findings of the fitting procedure for this study show that individuals have a bigger effect on bubbles that legal persons in the same span of time.
\end{abstract}

Keywords: Tehran Stock Exchange Market (TSE), Price bubble, individual and legal person trading, Market Efficiency, Rows Test, Stock Exchange Market (SEM), Stock Exchange (SE)

\section{Introduction}

Finance markets and especially capital market are one of the most important means of allocating and tooling financial resources. Any kind of distortion in these markets could impede the optimal allocation of resources. Price bubble, as one of the causes of these distortions, are based on a reaction developed as a result of the increase in the prices. Price increase leads to demand growth. Eventually, this surge of the demand on the part of the investors encourages them to expect higher returns in the future. However, as no upward trend could continue forever, when price increase culminates in its highest point, the loss return replaces the profit return and the increasing demand vanishes.

Bubble has been frequently used in relation to the prices of assets and especially stock prices. This seemingly simple word has a very complicated and controversial meaning, with scholars disputing over its meaning. According to Webster's dictionary, 'bubble" is anything lacking consistency, stagnancy, and reality. Meanwhile, according to Oxford Advanced learner's Dictionary, bubble is frail, baseless, hollow, and valueless. Economists have managed to develop some less subjective definitions, all-of-which share the concept of decline in time.

In his renowned paper on the history of financial crises, majid eshghi defines bubble as, "the upward movement of the asset price to the extent that it leads to a fall". Kindelburger's Palgrave Dictionary of economics defines bubble as, "the very fast and continuous surge of prices of an asset or a group of assets, starting with an initial increase and leading to an expectation of continuing increase in those new buyers -especially in the Stock Exchange Markets (SEM)- who tend to focus more on buying and selling stocks instead of focusing on developing profit return capacity".

Price bubbles are the results of those transactions in-which each of the individual and/or legal people involved can have an effect. In other words, in the process of bubble formation, the trading of some investors leads to the price bubbles. This paper attempts at studying the volume of transaction of individual and institutions in five-minute intervals so to determine their role in the formation of bubbles. 
Mcqueen et. al (1994) studied different types of bubbles in the markets. They concluded that there are 4 types of bubbles in the financial markets. These bubbles include:

1. Rational bubbles: when the bubble formation does not coincide any irrational behavior of the investors, there is rational bubble. Under these circumstances, although the investors are aware of the higher level of the basic value of the SEM, they still stay in the market. It might be due to the fact that they may believe that the bubble would probably continue growing bigger.

2. Intrinsic Bubbles: intrinsic bubbles result from basic factors. As the basic factors continue to grow and develop the news of this development lead to the continuation of the bubble growth.

3. Fads Bubbles: these bubbles result from psychological factors and the existence of a sense of ecstasy and joy within the people.

4. Information bubbles: if the prices do not depict all the information, the prices would deviate from basic value and form an information bubble.

\section{A Review of the Related Literature}

Increase in the profit and the decrease in the loss in investments are the major criteria for decision making in markets; nonetheless, at times, there are some behaviors in the investment markets, including SEMs, which are not in going with the basic principles of these markets. Under these circumstances, collective and reactive moves of the investors to buy or sell stocks can affect the prices without any logical or economic justification. This phenomenon is commonly referred to as the price bubble in the SEMs.

The concept of 'bubble' appeared in the financial studies in the $17^{\text {th }}$ century for the first time. From that time on, there have been many different bubbles in different financial markets all over the world. In Iran, in 2004, in the wake of the collapse of the TSE which took place after a period of significant boom, there were many questions in the mind of researchers. For example, Was this surge resulted from a bubble in the TSE?

One of the major signifiers of the existence of bubble is disbelief and heedlessness within most of the participants in the market. It should be mentioned that detecting when the participants leave sensible and systematic methods of assigning value to stocks for speculative behavior is a complicated process, while getting the signals for these behaviors is not that difficult.

In order to provide a clear picture of bubble in the SEM, the researchers provide Robert Shiller's account on the causes of the creation of bubbles. Shiller provides a historic discussion on bubbles and the root causes of them in the U.S. SEM in 1990s as well as the housing and SEM of the U.S. in 2003 to 2007. According to Shiller, there are 14 major causes for housing and SEM bubbles. Along with the basic factors, i.e. income surge or reduction in house hold expenditure, there are some cultural, psychological, demographic, as well as other factors, that are always present whenever there is a bubble in the asset markets. These factors include people's 'gust' to invest, active participation of pension funds, increase in the volume of online trading, increase in the number and participation of mutual funds, increase in the news on SEM in the media, significant increase in the volume of trades in the market, and significant increase in the ratio of the current market value to GDP. It was these very factors that led him to correctly predict the slump in the US SEM in 2000. Additionally, Shiller could predict the formation of bubble in housing and SEM in late 2007.

Individual and legal people's trading in TSE can have varied effects on price bubbles. The current paper aims at studying these effects through developing a model as well as studying the volume of trades. In the wake of developing the model, the TSE data would be fed into the model in the form of five-minute time series in order to implement the model.

Okapar (2010) studied bubbles through risk function. The findings proved that price bubbles resulting from speculation from 1984 to 2006 in Vietnamese SEM were not present. The positive and negative trains in the prices were independent from each other, and there was no durational dependence caused by positive and negative trains.

Bohel \& Silicus (2010) studied the existence of absence of price bubbles in the US SEM. The period of time under study extended from 1871 to the end of 2009. As the researchers doubted Dikifooler \& Dikifooler test, they employed MTAR technique. Based on the tests carried out, the researchers concluded that the stock prices depicted huge and bubbled deviations in their prices away from the fundamental values of the stocks in the short-run. This bubbled deviation would then lead to a drop, signifying balance in the stock prices in the long-run; therefore, no bubble was witnessed in the US SEM.

Himelbrg, et al. (2005), in their research to find out if SEM price bubbles were affected by investment firms, considered investors' behaviors and beliefs as well as short selling of stocks as causes of bubbles in SEMs. Fama ha (1981) studied the effect of governments' money and financial policies on the rise in stock prices so to find out the magnitude of these effects on bubbles. Based on their findings, bubbles formed were of rational type. 
Lamont (1998) studied price bubbles in Norway SEM and its effect on overall national economy from 1982 to 1997. Using West (1987) and Shiller Variance Test (1981), he rejected the null hypothesis of market efficiency where price bubbles are considered inexistent.

Engsted et al. (2001) developed a new price bubble diagnosis method to study US and UK SEMs from 1919 to 1999. They managed to reject the hypothesis for the inexistence of rational bubbles. Christophe (2003) came up with Blunchard \& Watson's test (1992) to certify bubbles in US SEM from 1871 to 2001. He also detected bubbles in French SEM from 1951 to 2002. Meanwhile, Christophe could reject the possibility of long-term bubbles both in US and French SEMs during the aforementioned years.

Using S\&P 100 index, Naseh \& Strauss studied bubbles for stock prices of 84 companies from 1979 to 2007. In so doing, they employed Panel's synergy test in the way to study the long-term relationship between price, DPS profits, and current value model test. Finally, they concluded that there is a cumulative relationship between stock price and DPS profits . Therefore, they rejected the existence of bubbles in the SEM.

\subsection{Research within Iran}

Vaez et al. (2008) in their paper on price bubble in the Iranian finance market employed Monte Carlo simulation technique to study price bubbles. The findings proved that the market deviated from a balanced long-term course of activity, proving the existence of bubbles in the Iranian finance market.

Gholipoor (2010) studied the effect of organizational investors in the development of bubbles for stock prices of companies privatized as per the $44^{\text {th }}$ article of the national Iranian constitution. He concluded that the whole statistical society under study had price bubbles.

Ma'adelat (2002) explained the true shape of stock index price changes as well as the price bubbles in TSE through formation shape method from 1999 to 2000 . He concluded that the existence of price bubbles in this period of time is evident. Basically, the unexpected price changes in this market intensified the probability of price bubble development.

Abassian et al. (2011) studied price bubbles within the framework of behavioral finance. In so doing, they supposed the arbitrage limitations, disturbing trading risks, and rational expectations, and concluded that even under the effect of the aforementioned items, the prices deviated from the fundamental descriptors of stock value. These findings highlight the importance of inflation and price/profit index in evaluating investment risk.

Yahyazade Far et al. (2009) in their study on rational price bubbles in TSE from May 2000 to May 2007 considered price bubble a type of unrealistic surge in prices, resulting from over-optimism of the market and leading to market fall. They employed three tests of fractional cumulative test, cumulative test, and unit-root test. All these three tests concluded that there was price bubble in TSE in the target period of time.

In his $\mathrm{PhD}$ thesis, Soltani (2007) studied price bubbles in TSE from 1991 to 2005 for 70 companies in the stock market. He employed inter-cumulative method to investigate inter-cumulating between the stock's real price for each and every company through Johanson inter-cumulating test in order to find the price bubbles for the stocks of these companies. The findings indicated that at $95 \%$ level of confidence, $55 \%$ of the companies under investigation had price bubbles.

Fallah Shams \& Zare (2003) studied the factors effective in the development of price bubbles in TSE from 2004 to 2009. Using skewness, curtosis, duration, and rows could prove the existence of price bubbles for the companies in the TSE. In order to predict bubbles they used such intrinsic variables of companies as company size, share holders' composition, $\mathrm{P} / \mathrm{E}$ ratio, information clarity, and pace of liquidity. They then used Binary Logit Regression and Artificial neural networks to predict price bubbles.

\section{Hypotheses}

Using the statement of problem as well as review of the related literature, two hypotheses were developed.

Hypothesis no. 1 : price bubble happened in TSE

Hypothesis no. 2 : the effect of transaction carried out by institutions is bigger than those of individuals.

\section{Data and Methodology}

As an applied research, this study employed correlation and regression analyses. The statistical society included all companies accepted in TSE up until March 2013. The sample population included 24 companies, sampled out through the following criteria:

- The company's shares had to be bought and sold in $70 \%$ of the time span.

- The stock return fluctuations had to be relatively big.

- The volume of company's shares being bought and sold in the SEM had to be enormous. 
The 24 companies which were chosen through improbablistic screening method made up for $26.87 \%$ of all SEM transactions in the target time interval. This was an indication of the huge volume of transactions for the samples.

The research data and information for this study included the price and volume of transactions for institutions and individuals separately. The informatics department of the TSE technology management company provided the data for this study. Through Excel software, the prices were divided in 5-minute-long time series. In addition, the transactions were grouped under the categories of individuals and institutions.

\subsection{Research Variables, Operational Definitions, and the Method to Calculate Variables}

This study aims at finding out if there are price bubbles, through tests to study the volume of transactions for individuals and institutions to see their effect size in the formation of price bubbles in TSE.

\subsection{Independent Variables}

Volume of transactions for institutions in 5-minute time series as well as those of individuals are the two independent variables.

\subsection{Dependent Variables}

The binary variable for the existence or inexistence of prices bubbles for companies with a 0 or 1 value. The values for this variable were calculated through stretching, skewness, and duration dependence tests. In case price bubble was present the value of 1 was assigned for the variable. If no price bubble was proved to be existent, the value of 0 was considered for the variable.

\subsection{Research Model}

The study got started with test to prove existence or non-existence of bubbles. Later, Binary Logit regression method was put into use to study the role of investors' investment - institutions and individuals- in the formation of price bubbles for stock prices. For the fitting of the model, the 5-minute time series data as well as the volume of transactions were put into use. The regression model for the study was defined as follows:

$$
B_{i}=\alpha_{i}+\beta_{1 i} T V_{i n, i}+\beta_{2 i} T V_{n o n, i}+\varepsilon_{i}
$$

Where $B_{i}$ is the price bubble for stock i. In case price bubble was there, the value of 1 considered for this variable. Otherwise, the value of 0 was considered for it.

$T V_{i n, i}$ The volume of tradings for institutions in 5-minute time series.

$T V_{\text {non }}$ The volume of tradings for individuals in 5-minute time series.

$\beta \quad$ The coefficients for the a.m. variables.

\section{Data Analysis}

The study got started with test to prove existence or non-existence of bubbles for the subjects of the research. The binary values were assigned for the existence or inexistence of price bubbles for companies. The values for this variable were calculated through rows stretching, skewness, and duration dependence tests, using SPSS software to-which the 5-minute time series data for the subject companies were fed. In case price bubble was present the value of 1 was considered for the variable. If no price bubble was proved to be existent, the value of 0 was considered for the variable.

In the second phase of this study, the research aimed at studying the magnitude of the effect of legal persons as well as individuals on the formation of bubbles. In order to assure a maximal informativeness, such tests as stationarity of dependent and independent variables and Dorbin-Watson test were put into use. In order to do so, Eviews7 software was used.

\section{Research Findings}

\subsection{Stationarity Test}

Prior to bubble tests and tests of the magnitude of the effect of institutions and individuals, stationarity test was carried out on all time series. As is obvious, unstationarity in any of the time series can lead to false regression, and eventually, statistical misinterpretations. In this study, the researchers first studied stationarity of 5-minute time series for the sample companies through Augmented Dickey-Fuller Unit Root Test. The results of this test for these companies is a follows. 
Table 1. Augmented Dickey-Fuller Unit Root Test on return time series of one of the samples ( Haffari Shomal Co.)

\begin{tabular}{cc}
\hline ADF statistic & $\mathbf{- 7 6 . 3 9 8 9 8}$ \\
\hline 1\% level & -3.430828 \\
5\% levle & -2.861636 \\
$10 \%$ level & -2.566862 \\
\hline
\end{tabular}

The test statistic was -76.398 , and the calculated $\mathrm{z}$ scores at $1 \%, 5 \%$, and $10 \%$ levels were $-3430,-2.861$, and -2.566 respectively. As the absolute value for these statistics were bigger that the critical values extracted from Table of Normal Standards, the null hypothesis, indicating unstationarity of the time series was rejected. In this way, the time series under study were stationed. This test was carried out for all of the time series, and the stationarity of all time series of the study were proved. In this way, the model could be carried out.

\subsection{Price Bubble Test in TSE}

In order to study existence or inexistence of price bubbles in TSE, rows test, skewness, and stretching were used. The findings are as follows:

\subsubsection{Rows Test}

This test was used to assure randomness of the sample. If the rows were not random, or were based on a pattern or trend, it could be concluded that the surge and drop of the prices were possible. In this way, it could be concluded that the price bubbles were present. If the absolute values of the test statistic were bigger than the critical value extracted from the Table of Normal Standards, it could be concluded that the return rows or prices were not random. Therefore, it could be concluded that the positive and negative rows were dependent on each other, signifying the existence of price bubbles during the span of time under study. This test was carried out for all samples' 5 -minute time series. Using the resulted statistics of this test as well as skewness and Stretching tests, 20 companies were suspected of having price bubbles. In other words, it could be said that the number of rows for these companies were meaningfully less than the expected rows. In addition, the length of positive and negative rows, in comparison to those of a random variable was significantly bigger. All these tests were carried out through SPSS software.

Table 2. The results of the rows test on return rows of two sample companies

\begin{tabular}{lcc}
\hline & Five-minute returns of company A & Five-minute returns of company B \\
\hline average returns & 0.03 & $\mathbf{0 . 1 1}$ \\
cases bigger than average & 7808 & $\mathbf{3 1 8 8}$ \\
cases equal to or smaller & 2214 & $\mathbf{1 7 0 5 5}$ \\
than the average & & \\
all observations & 10021 & $\mathbf{2 0 2 4 3}$ \\
number of rows & 3079 & $\mathbf{4 7 6 5}$ \\
Z statistic & -10.787 & $\mathbf{0 . 2 6 8}$ \\
level of meaningfulness & 0.000 & $\mathbf{0 . 0 0 5}$ \\
\hline
\end{tabular}

Critical values: for $95 \%$ level of confidence, it is 1.96, and for 99\% level of confidence, the critical value is 2.58

As can be seen in the table, the $\mathrm{z}$ score for company A is below levels of confidence; therefore, randomness of the positive and negative rows is rejected. In this way, company A can be considered to have a price bubble. However, as the $\mathrm{z}$ score for company B is within the level of confidence, it is improbable for company B to have price bubbles.

\subsubsection{Stretching and Skewness Tests}

Stretching shows the height of a distribution, i.e. it is a criterion for the height of the distribution curve at its maximum point. This figure for normal distribution is 3. A positive Stretching shows a higher pick for the distribution under study, and a negative Stretching signifies a lower that normal distribution pickedness for the target distribution.

Skewness is basically a criterion for the existence of symmetry within the normal distribution function. For a perfectly symmetrical distribution, the Skewness figure equals zero and for an asymmetrical distribution, it equals a figure else than zero. The most important index for Skewness is Skewness coefficient. If this coefficient is negative, the distribution skews left wards, while for a positive Skewness the distribution tends to the right hand side. The bigger the absolute value of skewness coefficient, the less symmetrical the target society's distribution would be.

In this section, if there is a negative skewness, it is possible for a price bubble to form. In the wake of price rises, the drop in the prices, resulting from the psychological atmosphere formed in the market, could be much more than the surge that took place in the market. In this way, if a stock has a negative skewness and less than normal Stretching, there is a price bubble. In order to calculate skewness and Stretching, SPSS software was put into use. Table 3 shows the results for two sample firms. 
Table 3. The results of Stretching and Skewness for returns of two sample firms

\begin{tabular}{crr}
\hline & 5-minute returns for company A & 5-minute returns for company B \\
\hline Number of input & 10021 & 20243 \\
Stretching & 2.336 & 156.854 \\
Skewness & -1.527 & 4.172 \\
\hline
\end{tabular}

In these two tests the critical values for skewness coefficient is 0 and for Stretching, it is 3. Obviously, in company A there was negative Skewness and below 3 stretching; therefore, the statistic for this test was out of the critical area. This showed that the company was among those which could have bubbles. Meanwhile, for company B Stretching was bigger that 3 and positive. The skewness was also positive. This signifies the inexistence of price bubble.

\subsection{Duration Dependence Test}

As with the duration dependence test, price bubbles happen when negative rows happen after positive rows and dependent on them. The process for duration dependence test is as follows:

1. Using ARMA the returns of the target stock was predicted. The formula for this prediction is as follows:

$$
\hat{R}_{t}=\gamma_{0}+\gamma_{1} R_{t-1}+\gamma_{2} R_{t-2}+\varphi_{t-1} \varepsilon_{t-1}^{2}+\varepsilon_{t}
$$

Where

$\hat{R}_{t}$ Is the nominal yield

$R_{t-1} \& R_{t-2}$ is the first and second pauses for variable $\mathrm{R}$

$\varepsilon_{t-1}^{2}$ is the square root for the first moving average, constituting model error

1. In this study, prior to developing a self-explanatory model for extracting estimated residue, stationarity tests were carried out for all time series.

2. After the model estimation, the residues were separated as positive and negative rows.

3. After the model estimation, the number of optimal intervals in the self-explanatory model was calculated through Box-Jenkins method. This is a method used in self-explanatory modeling where the number of optimal intervals are resulted from meaningfulness test for self-explanatory coefficients.

4. At this stage, the duration function is fit through logit regression test. In this function, the independent variable is the length of the rows. The dependent variable, on the other hand, is the binary variable. Assigning a value of 1 signifies negative rows and a value of zero is used for positive rows. The model is calculated through the following equation:

$$
\log i t(p)=\ln \left(\frac{p_{t}}{1-p_{t}}\right)=\alpha+\beta_{1} x_{1, i}+\ldots+\beta_{k} x_{k, t}
$$

5. in the duration dependence test if the negative rows depend on the length of the positive rows, one can conclude that the prices went up first and then dropped. This could probably be due to bubbles. However, if the prices were random, the positive and negative rows were independent. This could mean that no bubble took place. In order to do the risk test, the following formula was employed.

$$
h\left(t_{i}\right)=\frac{1}{1+e^{-(\alpha+\beta L n x i)}}
$$

Where $h\left(t_{i}\right)$ indicates the probability of a bubble. After fitting the model, if equals 1 , it can be concluded that no price bubble took place. What comes to mind at this stage is whether $\beta$ coefficients that were calculated through estimating risk function had any meaningful difference with one or not. In order to test this hypothesis, Wald test was put into use. Wald test is used to test implementation of limitations on a regression equation's coefficients. The null hypothesis in this test is $\beta=1$.

This test would be reported after the report on duration dependence test for two sample companies.

Table 4. Samples of the results of duration dependence test

\begin{tabular}{lcc}
\hline & bubble coefficient $(\beta)$ & Probability \\
\hline company A & $-/ 0065$ & $\mathbf{0 . 0 0 3 3}$ \\
company B & $-1 / 0077$ & $\mathbf{0 0 1 8}$ \\
\hline
\end{tabular}

According to Z-statistics, the level of meaningfulness for coefficients ( $p$-value), the determination coefficient, and the level of informativeness of the fit model, it can be inferred that in order to determine the probability of price bubbles this model is not of much efficiency. In the fit model, if $\beta=1$, there is no price bubble. 
Table 5. A summary for the results of Wald test for $\beta$ coefficient

\begin{tabular}{lll}
\hline & $\beta$ & Probability \\
\hline company A & $-1 / 099$ & $\mathbf{0 . 0 0 8}$ \\
company B & $-3 / 000$ & $\mathbf{0 . 7 4}$ \\
\hline
\end{tabular}

According to the calculated statistic as well as the level of meaningfulness for this model, the null hypothesis of $\beta=1$ for company A is rejected with $99 \%$ of confidence. Then, the price data for company A proves price bubble for it, while it is rejected for company $\mathrm{B}$.

Using the tests above, as well as duration dependence test, it is possible to estimate the probability of price bubbles for company A, with company B having no bubble. These three tests were used for all of the companies in the sample population. The findings indicated that out of 24 companies under study, 20 had price bubbles in the period of time when the study was carried out. Following, a report on the role of institutions and individuals is provided.

The results on the role of transactions carried out by institutions and individuals on price bubble. Using the research method, the volume of transactions for institutions and individuals were studied for the creation of price bubbles. In order to do so, the Logit Binary regression test was introduced. Moreover, the volume of 5-minute transactions for institutions was studied. Logistic modeling is superior to other modeling techniques in that the dependent variable can have two values, one-of-which is related to accidents in the market and the other on the existence of another bubble.

The regression model employed for this study is as follows:

$$
Z_{i}=\operatorname{Ln}\left(\frac{P_{i}}{1-P_{i}}\right)=\beta_{0}+\sum_{i=1}^{n} \beta_{0} X_{i}+\varepsilon_{i}
$$

Where Ln is the natural logarithm

Based on this model, the probability of price bubble for a share can be calculated through the following formula:

$$
P_{i}=\pi_{i}\left(x_{1}, x_{2}, x_{3}, \ldots x_{k}\right)=\frac{e^{\beta_{0}+\sum_{i=1}^{k} \beta_{i} x_{i}}}{1+e^{\beta_{0}+\sum_{i=1}^{k} \beta_{i} x_{i}}}
$$

Using the overall models above and the volume of transactions, the companies were separated based on the type of the investor, individual or legal persons, in 5-minute time series, the Eviews software was employed to study the role of these two types of investors in the formation of price bubble.

Based on the variables above and the research model suggested, the output of the software is reported as follows. This signifies the role and importance of each and every of the investor groups on price bubbles.

Table 6. The output of the software

Dependent Variable: B

Method: ML - Binary Probit (Quadratic hill climbing)

Date: 03/21/14 Time: 19:12

Sample: 1231281

Included observations: 231281

Convergence achieved after 16 iterations

Table 6. Covariance matrix computed using second derivatives

\begin{tabular}{lllll}
\hline \hline Variable & Coefficient & Std. Error & Z-Statistic & Prob. \\
\hline \hline C & 1.009283 & 0.003497 & 288.6398 & 0.0000 \\
IN & -3.628710 & 3.103209 & 0.116965 & 0.9069 \\
NON & -3.749006 & 5.978108 & 62.62337 & 0.0000 \\
\hline \hline McFadden R-squared & 0.017128 & Mean dependent var & 0.818126 \\
S.D. dependent var & 0.385741 & S.E. of regression & 0.382789 \\
Akaike info criterion & 0.932228 & Sum squared resid & 33888.64 \\
Schwarz criterion & 0.932362 & Log likelihood & -107800.3 \\
Hannan-Quinn criter. & 0.932267 & Deviance & 215600.6 \\
Restr. deviance & 219357.7 & Restr. log likelihood & -109678.8 \\
LR statistic & 3757.058 & Avg. log likelihood & -0.466101 \\
Prob(LR statistic) & 0.000000 & & 231281 \\
\hline \hline Obs with Dep=0 & 42064 & Total obs & \\
Obs with Dep=1 & 189217 & & \\
\hline \hline
\end{tabular}


Based on this table and the statistics above, and the amount of $\mathrm{Z}$ statistic, we can conclude that individual investors have a more effective role on price bubbles. In this way, the second null hypothesis for this study is rejected - the effect of transactions carried out by institutions is bigger than those of individuals.

In other words, the more transactions are carried out by individual investors, the more probable it is for price bubbles to take place.

\section{Discussion and Conclusion}

One of the major controversies amongst economic experts is the issue of price bubbles. They want to know if the stocks increase due to bubbles or because of some fundamental factors developed and improved, leading to a brighter economic prospect. In addition, the causes of price bubbles and the role of each of individual and institutions on price bubbles are of utmost importance in contemporary issues regarding bubbles.

At first through such tests as rows, skewness, stretching, and duration dependence, it was found out that price bubbles were formed in TSE in the span of time between May 2012 and November 2012. In this period, the prices were studied day by day, as well as in 5-minute time series. After doing bubble detection tests, the researchers divided the sampled companies under two categories of companies speculated to have bubbles and companies without bubbles. The study continued with investigating the effect of the behavior of individuals and legal persons on the formation of price bubbles. In so doing, their data on the transactions of individuals and legal persons were provided in 5 -minute time series. The logit binary regression model was then put to use so to find out the effect size of these groups according to the data available. The findings of the fitting procedure for this study show that individuals have a bigger effect on bubbles than legal persons in the same span of time.

According to the findings of this study, the following suggestions are suggested for avoiding bubbles:

1. Establishment as well as expanding market makers for absorbing excess demand in the market.

2. Establishment as well as expanding consultancies and analyzers for improving market efficiency.

3. Taking adequate measures for improving stock liquidity by SE organization and other authorities.

4. Obliging SE organization to implement the act on transparency of companies.

5. Taking appropriate measures to control activities of individual investors.

\section{References}

Abbasian, et al. (2010). Recognizing stock price bubble in TSE through current value model. Economic Studies, 17(60), 75-92.

Azar, A., \& Momeni, M. (2001). Statistics and its application in management. Tehran: Samt Publications.

Blanchard, O. (1992). Speculative Bubbles, Crashes and Rational Expectations, Economics Letters, 387-389.

Bohl, M. T, \& Sikolos, P. L (2010). The present value model of Us stock prices reduce: a new testing strategy and some evidence, the quarterly review of economics and finance.

Christophe, B. (2003). Testing for Rational Bubbles with Time Varing Risk Premium and Non- Linear Cointegration: Evidence from the USA and French Stock Markets. University Paris Nord. CEPN, France, Version. November.

Engsted, T., \& Tanggard, C. (2001). A New Test for Speculative Bubbles Based onReturn Variance Decompositions. Department of Finance, the ArhusSchool of Business Denmark Publication.

Eshghi, M. (2006). Studying stock price bubble in companies listed in TSE (Unpublished Master's Thesis). Imam Sadegh University, Tehran, Iran.

Fadaei Nejad, M. (1995).Test of weak form of effecency and TSE. Journal of financial research, 5, 3-26.

Fallah Shams, M. F., \& Zare, A. (2013). A study on the factors effective in the formation of price bubbles in TSE. TSE Journal, 21, 73-91.

Fama ha. (2010). Stock Returns, Real Activity, Inflation and Money. American Economic Review, 4(71).

Gholipour, M. (2010). A study on the effect of institutional investment on the formation of stock price bubbles (Unpublished Master's thesis).

Lamont, O. (1998). Earnings and Expected returns. Journal of Finance, 53. PP, 1563-1587. http://dx.doi.org/10.1111/0022-1082.00065

Larsen, E. S. (1997). Theories and Tests for Bubbles. Working Papers of Universitetet i Tromso, 17-19.

Mcqueen, G, \& Torley, S. (1994). Bubbles, Stok Returns, and Duration Dependence. Journal of Financial and Quantity Analysis, 29, 379. http://dx.doi.org/10.2307/2331336 
Moadlat, K. (2002). A study on price bubbles in TSE for years ago. Selections of economics project, $20,24$.

Nasseh, A., \& Strauss, J. (2010). Stock prices and the dividend discount model: did their relation break down in the 1960s? The quarterly review of economics and finance, 44, 191-207. http://dx.doi.org/10.1016/j.qref.2003.09.001

Okpara, G. (2010). Do Rational Speculative Financial Bubbles Exist in theNigerian Stock Market? Interdisciplinary Journal of Contemporary Researchin Business.

Samadi, et al. (2007). Efficiency test and price bubble in TSE through filter principle and CAPAM pattern. Economic studies, 4(4), 91-113.

Shiller, Robert J. (1989). Market Volatility. Cambridge: MIT Press.

Soltani, A. (2007). A study on TSE price bubbles from 1991 to 2005 (Unpublished Doctoral dissertation). Shahid Beheshti University, Tehran, Iran.

Vaez, M., \& Torki, L. (2009). Price bubbles and capital market in Iran. The Journal of Esfahan University, 31(3), 195-207.

Westerhof, F. (2003). Bubbles and Crashes: Optimism, Trend Extrapolation and Panics. Journal of Theoretical and Applied finance, 6(8), 829-837. http://dx.doi.org/10.1142/S0219024903002237

Yahyazadeh, F. M., Taghinejad, V., \& Alipour, S. (2009). A study on price bubbles in TSE. Nameh Mofid, 72, 49-68.

\section{(cc) EY}

This work is licensed under a Creative Commons Attribution 3.0 License. 